
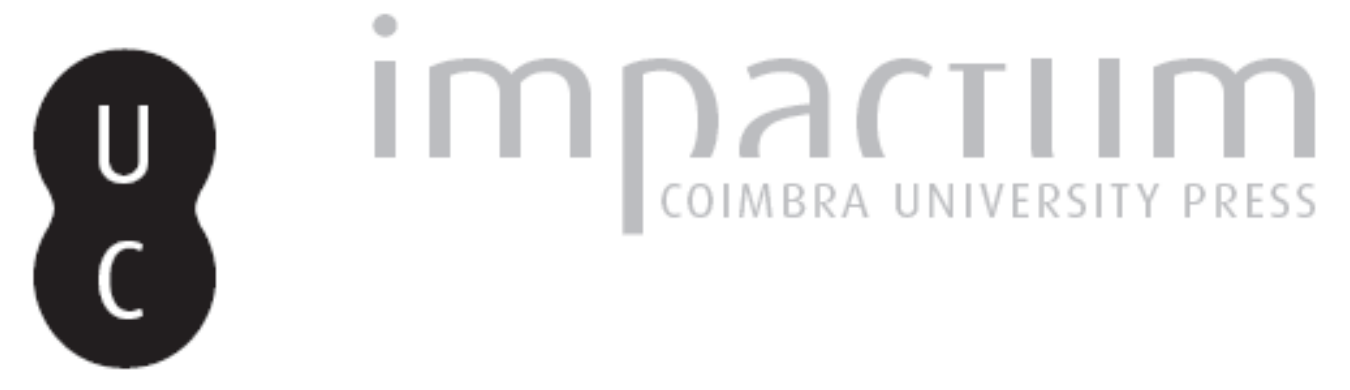

\title{
Casais agrícolas da Idade do Ferro na Foz do Mondego
}

Autor(es): Pereira, Isabel

Publicado por: Imprensa da Universidade de Coimbra

URL persistente:

URI:http://hdl.handle.net/10316.2/45477

DOI:

DOI:https://dx.doi.org/10.14195/1647-8657_32_33_3

Accessed : $\quad$ 26-Apr-2023 16:26:05

A navegação consulta e descarregamento dos títulos inseridos nas Bibliotecas Digitais UC Digitalis, UC Pombalina e UC Impactum, pressupõem a aceitação plena e sem reservas dos Termos e Condições de Uso destas Bibliotecas Digitais, disponíveis em https://digitalis.uc.pt/pt-pt/termos.

Conforme exposto nos referidos Termos e Condições de Uso, o descarregamento de títulos de acesso restrito requer uma licença válida de autorização devendo o utilizador aceder ao(s) documento(s) a partir de um endereço de IP da instituição detentora da supramencionada licença.

Ao utilizador é apenas permitido o descarregamento para uso pessoal, pelo que o emprego do(s) título(s) descarregado(s) para outro fim, designadamente comercial, carece de autorização do respetivo autor ou editor da obra.

Na medida em que todas as obras da UC Digitalis se encontram protegidas pelo Código do Direito de Autor e Direitos Conexos e demais legislação aplicável, toda a cópia, parcial ou total, deste documento, nos casos em que é legalmente admitida, deverá conter ou fazer-se acompanhar por este aviso.

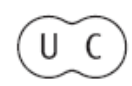




\section{UNIVERSIDADE DE COIMBRA \\ FACULDADE DE LETRAS}

\section{CONIMBRIGA}

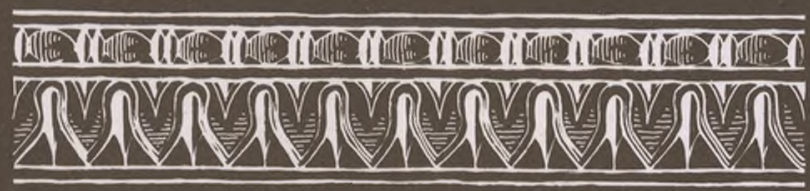

VOLUMES XXXII-XXXIII-1993/94 


\section{ISABEL Pereira}

Conservadora do Museu Municipal Dr. Santos Rocha (Figueira da Foz)

\section{CASAIS AGRÍCOLAS DA IDADE DO FERRO}

NA FOZ DO MONDEGO - FIGUEIRA DA FOZ

«Conimbriga» XXXII-XXXIII (1993-1994), p. 75-85

Resumo: Entre os finais do séc. VII e os inícios do V a. C., na área da foz do Mondego, para além dos povoados bem conhecidos de Santa Olaia e Crasto de Tavarede, havia casais agrícolas que a autora aqui identifica, publicando os materiais neles recolhidos por Santos Rocha.

RÉsumé: Dans la rive droite de l'embouchure du Mondego, en plus des deux oppida identifiés de Santa Olaia e Crasto de Tavarede, il y avait, entre la fin du Vllème et le début du Vème siècle avant Jésus-Christ, des petites granges que Fauteur identifie d'après les travaux réalisés par Santos Rocha au début du siècle. 
(Página deixada propositadamente em branco) 


\section{CASAIS AGRÍCOLAS DA IDADE DO FERRO NA FOZ DO MONDEGO - FIGUEIRA DA FOZ}

\section{INTRODUÇÃO}

Os estudos pioneiros de Santos Rocha, durante o séc. XIX e inícios do séc. XX, dão-nos a conhecer os vários tipos de povoamento, durante a Idade do Ferro, na Foz do rio Mondego, ou seja, a juzante de Montemor-o-Velho, no Concelho da Figueira da Foz.

Desses estudos, Santa Olaia - Ferrestelo, Crasto em Tavarede, Lírio e Bizorreiro de Castela impõem-se como povoados, sobre colinas de baixa e média altitude, dominando vales férteis, com água e bons terrenos de agricultura. São, por outro lado, sítios estratégicos na defesa e comunicação, dominando territórios alargados.

Arieiro, Chões, Fonte de Cabanas e Pardinheiros aparecem, por seu lado, como pequenos núcleos populacionais, vivendo da agricultura, pastoricia e artesanato, localizados em vales com óptimas capacidades agrícolas.

Em 1970, no II Congresso Nacional de Arqueologia, realizado em Coimbra, A. de Victor Guerra e O. da Veiga Ferreira retomam os estudos, anteriormente iniciados, e elaboram o "Inventário das Estações da Idade do Ferro nos Arredores da Figueira da Foz".

No presente estudo, não consideramos o fundo de Cabana de Santo Amaro da Serra (a $200 \mathrm{~m}$ a O. da Mama do Furo, no Prazo de Santa Marinha), registado por Victor Guerra e Veiga Ferreira. A análise pormenorizada do material existente no Museu Municipal do dr. Santos Rocha, Figueira da Foz, aponta, inequivocamente, para uma ocupação da época Neolítica. 


\section{CASAIS RURAIS}

\section{Arieiro}

O lugar do Arieiro, freguesia de Brenha, situa-se a Oeste das Alhadas e a Leste de Brenha, a 98 metros de altitude (P-359.900; M-142.000, folha 239 da carta militar de Portugal, 1947).

Conhecemos o lugar pelo catálogo do Museu Q) “6351 a 6374 - Espólio em ferro e cerâmico, recolhido em Arieiro, Freguesia de Brenha (transição para a época romana?)".

De todo o espólio mencionado pelo escavador foram individualizados, no Museu, os fragmentos em ferro, de forma indefinida, mais precisamente, restos de escória.

No lugar não foram identificadas estruturas arqueológicas.

\section{Chões}

A norte da Freguesia de Brenha, exposta aos ventos norte, a 90 metros de altitude localiza-se o lugar de Chões (P-359.000; M-141.000, folha 239 da carta militar de Portugal, 1947).

Desenvolve-se a Norte, Leste e a Oeste um vale fértil, rico em água. A Sul, eleva-se uma suave vertente onde Santos Rocha escavou duas estruturas de habitações da Idade do Ferro. A Norte, outras foram detectadas mas não escavadas. A distância entre os dois depósitos não excedia os três metros e a diferença de nível rondava os setenta centímetros. Diz Santos Rocha que "ambos os depósitos tinham a espessura máxima de $0,50 \mathrm{~m}$. Estavam fortemente empastados e eram constituídos por terra vegetal carregada de carvão, cinzas, ossos de animal e fragmentos de cerâmica". São vestígios que não foram atingidos pelas culturas do terreno pois ocupavam " a parte mais funda da espécie de fossas em que assentavam as cabanas. $O$ fundo destas fossas era formado pelo solo natural, composto de argila amarelada, e em parte, pelo menos parecia revestida com cascalho" (2).

Pela descrição de Santos Rocha e pela presença de habitações cujos pavimentos e partes superiores de muros e coberturas foram des- ${ }^{(\cdot)}$

(•) RochA, António dos Santos - O Museu Municipal da Figueira da Foz. Catálogo Geral. Figueira da Foz, Imprensa Lusitana, 1905, p. 138

(2) Rocha, António dos Santos - Chões e Pardinheiros, in "Memórias e Explorações Arqueológicas", voi. 2, Coimbra, 1971, p. 133-136.

Conimbriga, 32-33 (1993-1994), 75-85 
cobertas, estamos perante habitações rurais que faziam da agricultura o seu modo essencial de vida.

A homogeneidade do espólio exumado $\left(^{3}\right)$ permite-nos concluir por uma ocupação entre finais do Séc. VII a inícios do Séc. V a. C.

\section{MATERIAIS ARQUEOLÓGICOS:}

1 e 2) Contas de colar, argila clara, feitas à mão, perfuradas, barriloides. (Est. II) N. ${ }^{\circ}$ de inv. 2399 A e 2399 C.

3) Conta de colar, cinzenta escura, feita à mão, perfurada, oblonga (Est. II) N. ${ }^{\circ}$ de Inv. 2399 B.

4) Cossoiro, de cerâmica vermelha, feito à mão, pasta grosseira, calcífica, perfurado, em forma de cone duplo. (Est. II).

Sem número de inventário.

5) Cossoiro de cerâmica vermelha, feito à mão, pasta grosseira, calcítica, perfurado, em forma de cone duplo com decoração linear (Est. II).

Sem número de inventário.

6) Fragmento de pulseira, de bronze, de secção circular (Est. II). Sem número de inventário.

7) Fragmento de bordo de taça, cinzento escuro, com carena pouco pronunciada, feito à mão, pasta fina, clara, (Est. III).

Sem número de inventário.

8) Fragmento de bordo e pança de tigela, hemisférica, de lábio afilado, cinzento escuro, feito à mão, pasta fina. (Est. III).

N. ${ }^{\circ}$ de Inv. 2635.

9) Fragmento de bordo e pança de tigela, hemisférica, de lábio afilado, feito à mão, pasta fina escura, com mica, coberta com engobe vermelho, polido (Est. III).

N. ${ }^{\circ}$ de Inv. 2634.

10) Fragmento de bordo e pança de tigela, hemisférica, de lábio afilado, feito à mão, pasta escura com mica, com vestígios de engobe vermelho no exterior (Est. III).

Sem número de inventário.

11) Fragmento de bordo e pança de tigela, hemisférica, de lábio afilado, feita à mão, pasta escura com desengordurante e mica, de cor irregular, do castanho amarelado ao negro, polida (Est. III).

Sem número de inventário.

(3) Rocha, António dos Santos - O Museu Municipal da Figueira da Foz. Catálogo Geral. Figueira da Foz, Imprensa Lusitana, 1905, p. 136-137.

Conimbriga, 32-33 (1993-1994), 75-85 
12) Fragmento de bordo de tigela, com carena pouco pronunciada, feita à roda, pasta fina clara, com mica, paredes de cor cinzenta, polida (Est. III).

N. ${ }^{\circ}$ de Inv. 2632.

13) Fragmento de tigela, com ligeiro estrangulamento junto ao bordo, feita à roda, pasta fina clara, com mica, paredes de cor cinzenta, polida (Est. III). N. ${ }^{\circ}$ de Inv. 2631.

14) Fundo de tigela, em onfalo, de pasta clara, fina, com mica e paredes de cor cinzenta, polida (Est. III).

N. ${ }^{\circ}$ de Inv. 2633.

15) Fragmento de bordo e pança de tigela, campanular de bordo afilado, ligeiramente voltado para o exterior, de cerâmica feita à mão, pasta escura com calcite e mica, cor entre o castanho e o amarelo (Est. III).

N. ${ }^{\circ}$ de Inv. 2621.

16) Fragmento de bordo e colo, de grande pote, de colo alto, bordo liso e voltado para o exterior, de cerâmica feita à mão, pasta clara, calcítica, com mica, cor amarelada (Est. III).

N. ${ }^{\circ}$ de Inv. 2613.

17) Fragmento de bordo e colo, de grande pote, feito à mão, de bordo voltado para o exterior, de cerâmica cinzenta clara, com muita mica, colo decorado com traços paralelos incisos ligeiramente inclinados (Est. III).

N. ${ }^{\circ}$ de Inv. 2358.

18) Fragmento de bordo, de grande pote, de cerâmica cinzenta, feita à mão, pasta clara com muita mica, colo com decoração impressa em sulcos oblíquos e paralelos (Est. III).

N. ${ }^{\circ}$ de Inv. 2357.

19) Bordo e colo de grande pote, de colo alto, bordo voltado para o exterior, denteado, de cerâmica feita à mão, de pasta cinzenta calcítica, paredes de cor avermelhada. (Est. III).

Sem número de inventário.

20) Fragmento de bordo e colo, de grande vaso, de colo alto e bordo plano, denteado, de cerâmica feita à mão, pasta calcítica escura, parede externa avermelhada (Est. IV).

N. ${ }^{\circ}$ de Inv. 2596.

21) Fragmento de colo, de pequeno vaso, com asa de secção em "oito", bordo liso, virado para fora, feito à mão, pasta calcítica escura, parede exterior acastanhada (Est. IV).

N. ${ }^{\circ}$ de Inv. 2281 A.

22) Fragmento de bordo e colo, de pequeno vaso, com asa de secção elíptica, bordo liso, virado para fora, feito à mão, pasta calcítica e com mica, escura, parede exterior de cor negra e avermelhada (Est. IV).

N. ${ }^{\circ}$ de Inv. 2281. 
23) Fragmento de bordo de prato, hemisférico, de bordo acentuadamente virado para dentro, formando carena, feito à roda, de cerâmica cinzenta escura, fina, polida, com muita mica (Est. IV).

Sem número de inventário.

24) Fragmento de bordo de prato, hemisférico, de bordo ligeiramente voltado para o interior, formando carena pouco acentuada, feito à roda, de cerâmica cinzenta escura, fina, polida, com muita mica (Est. IV).

Sem número de inventário.

25) Fragmento de bordo de prato, hemisférico, de bordo virado para dentro, ligeiramente espessado no interior do bordo, feito à roda, de cerâmica escura, fina, polida, com muita mica (Est. IV).

Sem número de inventário.

26) Fragmento de bordo de prato, hemisférico, feito à roda, perfurado, com a parede exterior e bordo de cor cinzenta escura, parede interior cinzenta clara. Pasta fina, com mica (Est. IV).

Sem número de inventário.

27) Fragmento de bordo de prato, hemisférico, de lábio ligeiramente voltado para o interior, feito à roda, de cerâmica escura, fina, polida, com mica. Grafito na parede exterior (Est. IV).

Sem número de inventário.

28) Fragmento de bordo de prato, carenado, imitando forma de engobe vermelho, feito à roda, de cerâmica cinzenta escura, fina, polida. Pasta fina, com mica (Est. IV).

N. ${ }^{\circ}$ de Inv. 2628.

29) Fragmento de prato, carenado, imitando a forma de prato de engobe vermelho, com a parede interior rosada e a exterior cinzenta escura. Pasta fina, dura, com mica, rosada (Est. V).

Sem número de inventário.

30) Fragmento de bordo de prato, carenado, de engobe vermelho. Pasta bege, rosada, fina e dura, com mica (Est. V).

N. ${ }^{\circ}$ de Inv. 2564.

31) Fragmento de bordo de prato, carenado, de engobe vermelho, polido, no interior. Pasta bege, dura, com mica (Est. V).

Sem número de inventário.

32) Fragmento de bordo de prato, hemisférico, com o bordo virado para o interior, feito à roda, com engobe vermelho aguado na parede interior. Pasta bege, fina, dura, com mica (Est. V).

Sem número de inventário.

33) Fragmento de tigela, carenada, rosada, feita à roda, pasta muito dura, fina, com mica (Est. V).

Sem número de inventário. 
34) Fragmento de bordo de tigela, campanular, feita à roda, com o bordo engrossado virado para o exterior, cor bege, pasta cinzenta, dura, com muito desengordurante (Est. V).

Sem número de inventário.

35) Fragmento de bordo e pança de pequeno pote, feito à roda, com o bordo engrossado no interior, voltado para o exterior. Pasta cinzenta, dura, com desengordurante (Est. V).

Sem número de inventário.

36) Fragmento de bordo e asa de pequeno vaso, feito à roda, com o bordo voltado para o exterior, asa com ranhura a meio, paredes de cor bege. Pasta cinzenta, dura, com desengordurante (Est. V).

N. ${ }^{\circ}$ de Inv. 2639.

37) Fragmento de colo e pança, de grande vaso, feito à roda, de cor bege, pasta clara com desengordurante e mica (Est. V).

Sem número de inventário.

38) Fragmento de bordo e colo de grande pote, com o bordo virado para o exterior, de cerâmica feita à roda, cor castanha amarelada, pasta cinzenta, com muito desengordurante e mica (Est. VI).

Sem número de inventário.

39) Fragmento de bordo e de colo de vaso, feito à roda, com o bordo virado para fora, plano, cor bege, pasta cinzenta clara, com desengordurante e mica (Est. VI).

Sem número de inventário.

40) Fragmento de bordo e colo de vaso, feito à roda, com o bordo virado para o exterior, plano, com ligeira carena no interior, cor bege, pasta cinzenta clara, com desengordurante e mica (Est. VI).

N. ${ }^{\circ}$ de Inv. 2576.

41) Fragmento de bordo e colo de vaso, feito à roda, com o bordo ligeiramente engrossado, virado para o exterior, com carena suave no interior, cor bege, pasta cinzenta clara, com desengordurante e mica (Est. VI).

Sem número de inventário.

42) Fragmento de asa de ânfora, bipartida, de secção em "oito", cor bege, pasta cinzenta clara, com muito desengordurante e mica (Est. VI).

N. ${ }^{\circ}$ de Inv. 2379 A.

43) Fragmento de adobe, cor vermelha, com vestígios de ramos vegetais impressos em negativo (Est. VI).

N. ${ }^{\circ}$ de Inv. 2351.

\section{Fonte de Cabanas}

Perto da Fonte de Cabanas, à altitude de 160 metros, na freguesia de Brenha, escavou Santos Rocha restos de cinco estruturas "circulares,

Conimbriga, 32-33 (1993-1994), 75-85 
abertas no tufo calcário, com o diâmetro de $1,45 \mathrm{~m}$, muito próximos entre si, conservando ainda algumas d'elas a profundidade de 0,60 m"( $\left.{ }^{4}\right)$. O fundo era côncavo e continha terra com carvões, cinzas e conchas (P-358.900; M-140.200; folha 239 da carta militar de Portugal, 1947).

Perto destas estruturas foram encontrados fragmentos de cerâmica, feita à mão, idêntica às exumadas no Castro, Tavarede. No catálogo do Museu, o espólio foi registado com o número $4731\left(^{5}\right)$.

Santos Rocha mostra algumas hesitações em relacionar os achados com as estruturas escavadas.

\section{MATERIAL ARQUEOLÓGICO:}

1) Fragmento de bordo e colo de grande pote, de colo alto e bordo adelgaçado, feito à mão, pasta clara com mica, e calcite de cor amarelada e acabamento brunido.

Sem número de inventário.

2) Fragmento de cerâmica comum avermelhada, feita à roda, pasta com mica e calcite.

Sem número de inventário.

\section{Pardinheiros}

$\mathrm{Na}$ freguesia de Quiaios, no vale que se desenvolve entre as Pedras da Bandeira e a Corredoura, a Leste, e os montes Lamasmas e Alqueves, a Oeste, situa-se sensivelmente a 100 metros de altitude o sítio dos Pardinheiros (P-360.130; M-137.000, folha 228 da carta militar de Portugal, 1947).

Das inúmeras sondagens efectuadas por Santos Rocha, conclui-se da existência de uma estação da Idade do Ferro $\left(^{6}\right)$. Não apareceram estruturas e os materiais arqueológicos apresentavam-se misturados - cerâ-

(4) Rocha, António dos Santos - Silo préhistorico da Rendinha. "Boletim da Sociedade de Archeologia Santos Rocha", Tomo 1(7), Figueira, Imprensa Lusitana de Augusto Veiga, 1908, p. 197.

(5) RochA, António dos Santos - O Museu Municipal da Figueira da Foz• Catálogo Geral. Figueira, Imprensa Lusitana, 1905, p. 138.

(6) RochA, António dos Santos - Memórias e Explorações Arqueológicas, voi. 2, Coimbra, 1971, p. 136. 
micas da Idade do Ferro, Romanas e Medievais. Nas reservas do Museu não foi identificado o espólio da Idade do Ferro, nomeadamente o fragmento de cerâmica pintada com paralelo nas cerâmicas de Santa Olaia.

Uma plantação recente de eucaliptos, efectuada em 1986, em propriedade dos Srs. Arlindo Custódio Machado e Luís Machado Abreu, levou-nos ao local. Aqui, na camada mais profunda, de cinzas, muito gordurosa, com cascas de marisco, foi possível observar a existência de pequenos fragmentos de cerâmica tardia, misturada com pequeníssimos fragmentos de cerâmica cinzenta, de perfis não identificáveis.

Mesquita de Figueiredo, nas suas notas manuscritas (Livro 5, fis. 5 verso, 15 verso e 28 verso) anota que em Pardinheiros, próximo do Cabo Mondego, existem despojos romanos e que aí encontrou um fragmento de telha e de "imbrex". Não faz referência a materiais atribuíveis à Idade do Ferro.

\section{CONCLUSÕES}

1) Toda a ocupação humana nos casais agrícolas era pouco densa, e ocupava sítios amparados dos ventos, em vales de bons terrenos e com muita água.

2) Os pavimentos das habitações rurais da Idade do Ferro, eram de argila batida, revestidos ou não de cascalho - Chões e Fonte de Cabanas.

3) A parte superior dos muros era construído com a técnica usual em Santa Olaia: elementos vegetais cobertos de argila.

4) Desconhece-se a forma generalizada das habitações. Todavia as habitações de Fonte de Cabanas eram circulares, abertas no tufo calcário. Os restantes arqueo-sítios foram identificados pelos materiais exumados ou restos de pavimentos de forma indeterminada.

5) Como materiais arqueológicos predominam as cerâmicas grosseiras, feitas à mão com paralelo nas exumadas em Crasto, Tavarede. Todavia, não são estranhas as cerâmicas de importação, com paralelo em Santa Olaia, nomeadamente nas estações de Chões e Pardinheiros.

6) Rareiam os objectos metálicos. Em Arieiro apareceram fragmentos de escória de ferro, apontando no sentido da prática da metalurgia no local.

7) Só Chões fornece um fragmento de objecto em bronze (est. II, n. ${ }^{\circ} 6$ ), identificado como pulseira. 
8) A existência de cossoiros em Chões indica a prática de tecelagem nos casais agrícolas durante a época em estudo.

9) O exame dos materiais aponta para uma cronologia de ocupação datada dos finais do Séc. VII a inícios do Séc. V a. C. Existem cerâmicas, inequivocamente, datadas do Séc. VI, nomeadamente em Chões e Pardinheiros. Todavia, a ausência de cerâmicas mais recentes, encontradas em Santa Olaia e Crasto de Tavarede, concretamente as cerâmicas estampilhadas, apontam para o desaparecimento destes casais antes da entrada em decadência de Santa Olaia e Crasto. Os materiais exumados correspondem ao período mais antigo e rico daqueles dois importantes povoados. 


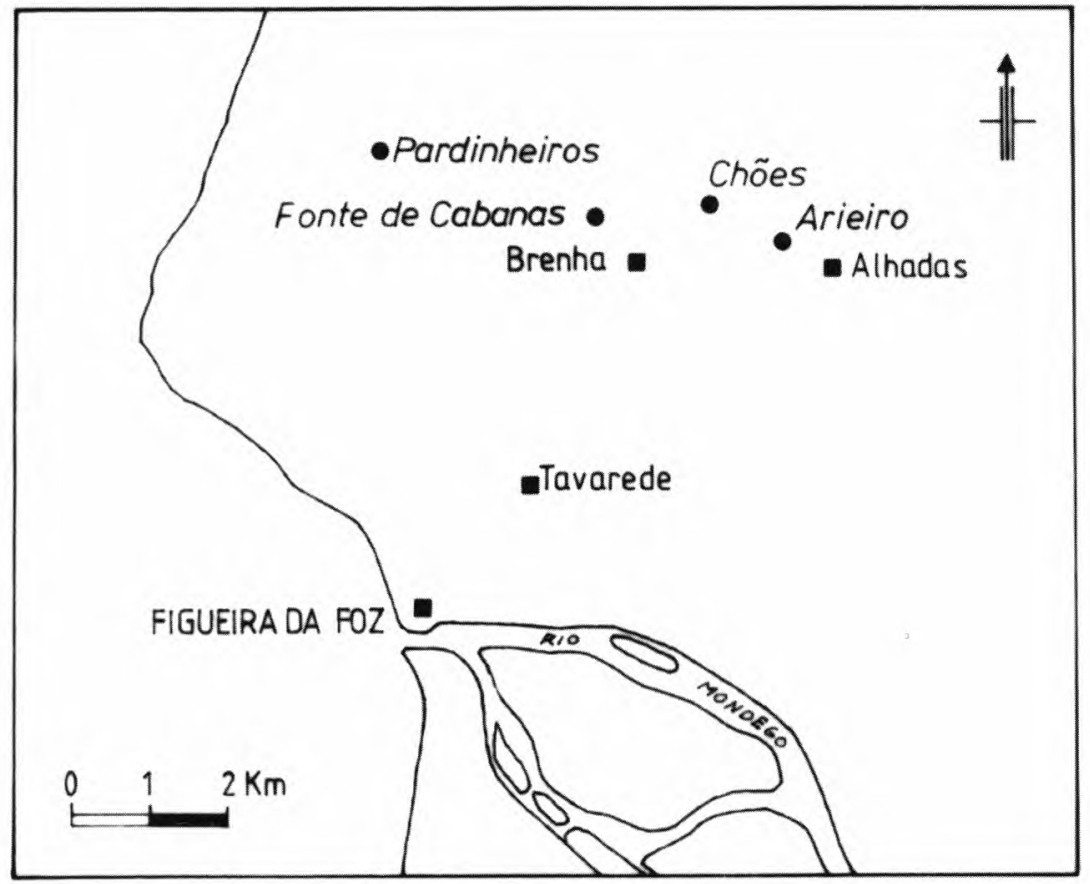

- Povoaçōes actuais

- Casais da Idade do Ferro 
EST. II
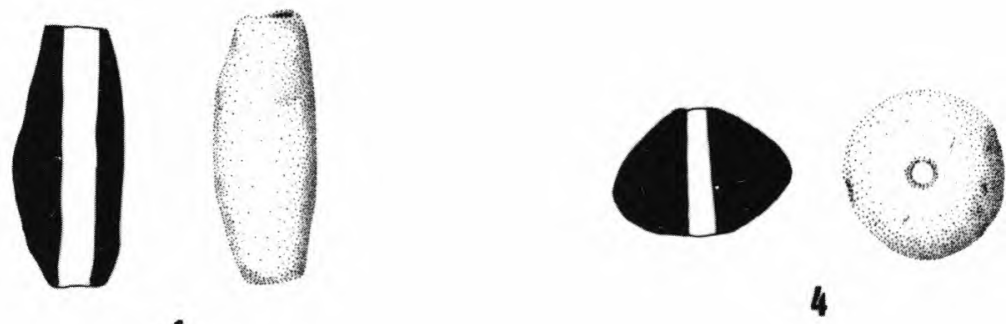

1
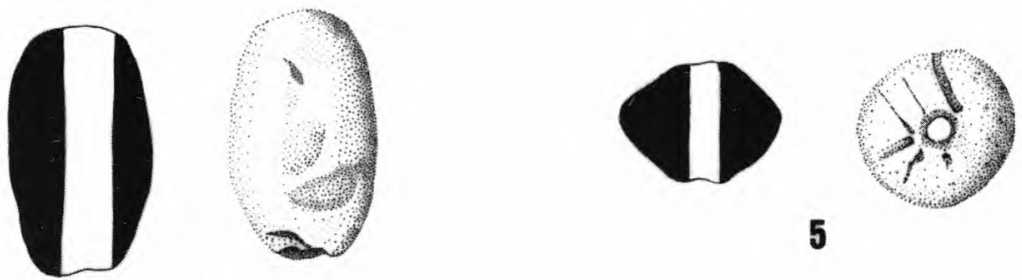

5

2
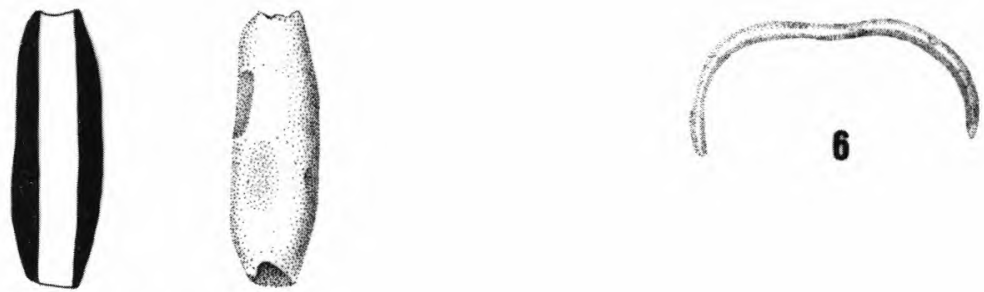

3

Esc. 1: 4 aprox. 
EsT. Ill

1

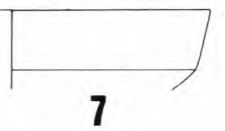

7

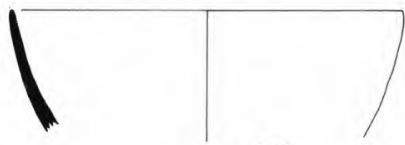

10

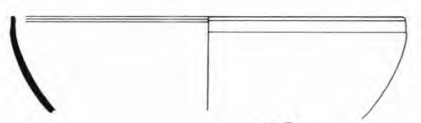

13

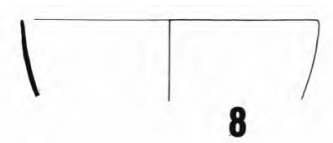

8

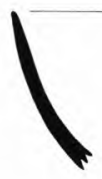

11
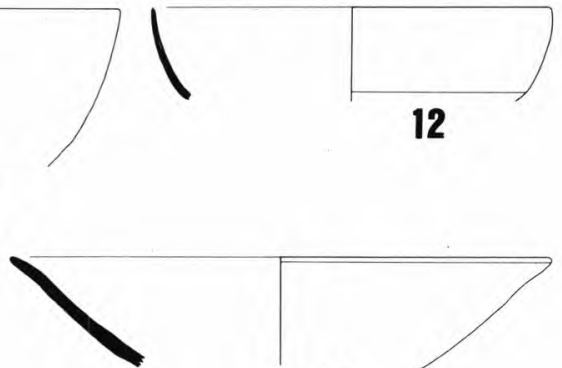

12

14
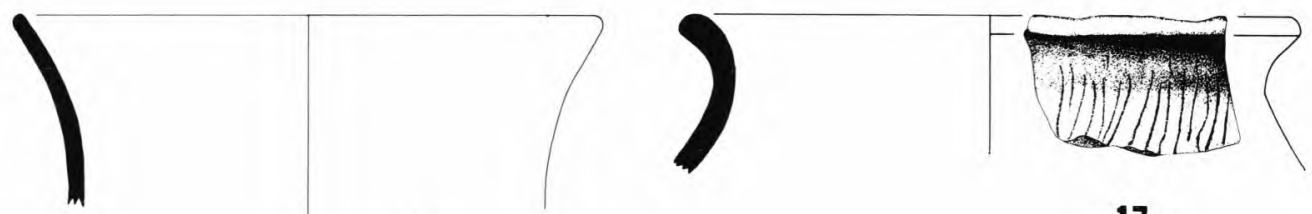

16

15
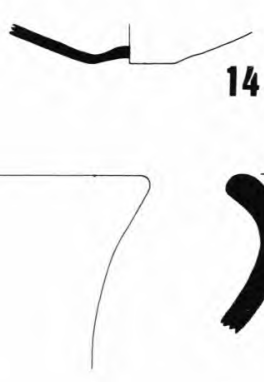

17

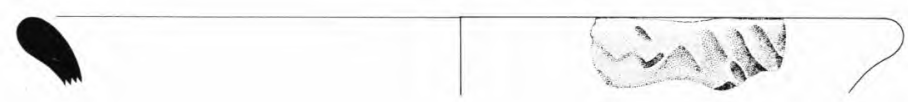

18

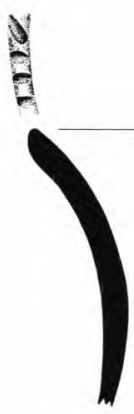

19

Esc. 1: 4 aprox. 
Est. IV
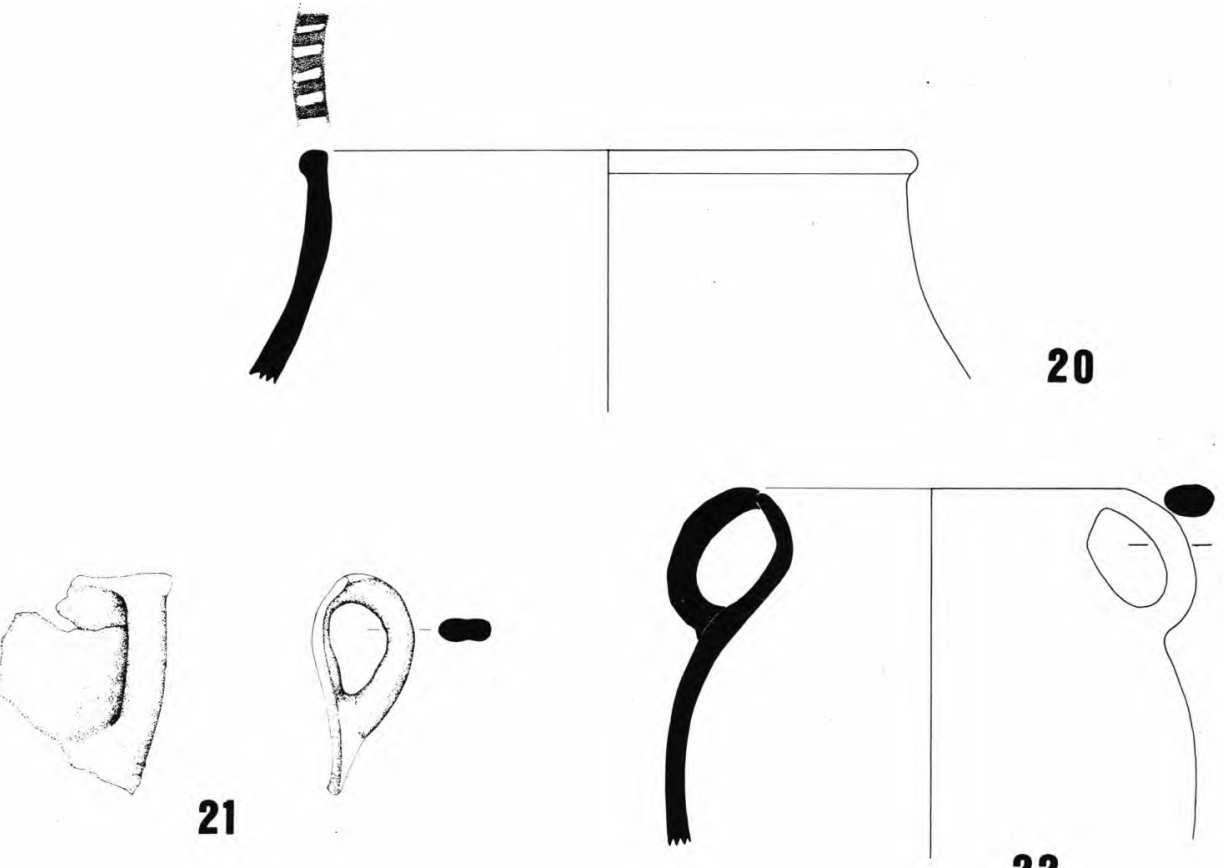

22

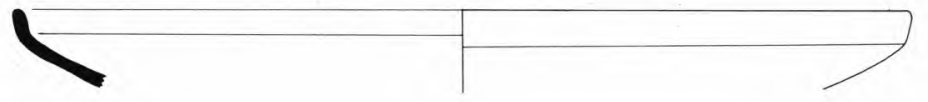

23
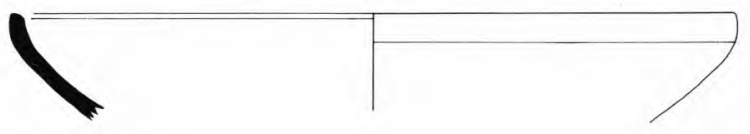

24

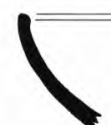

25

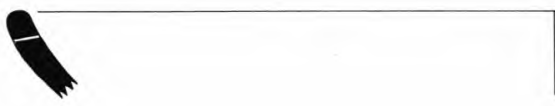

26
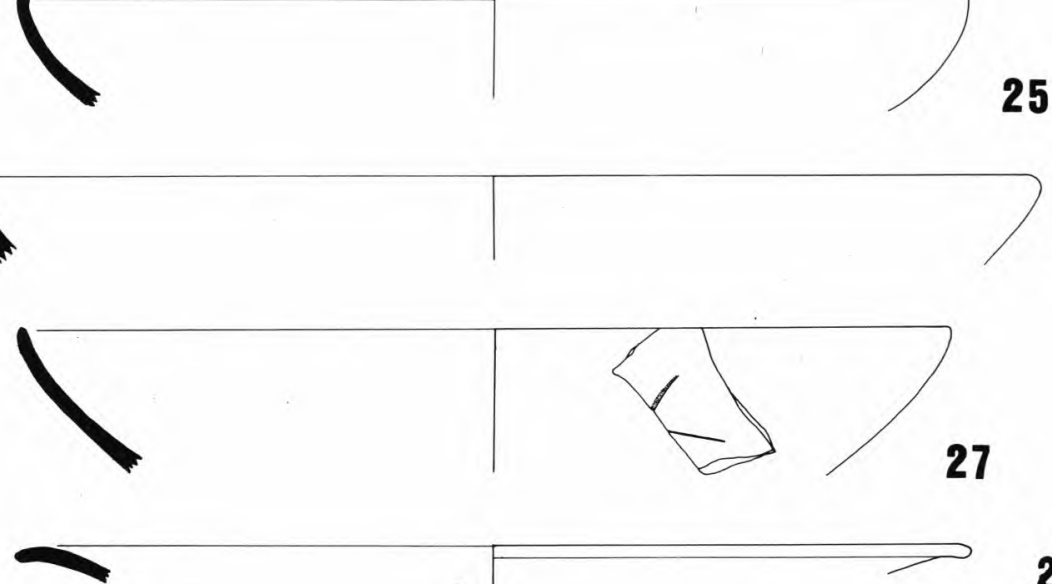

27

28

Esc. 1: 4 aprox. 
EST. V
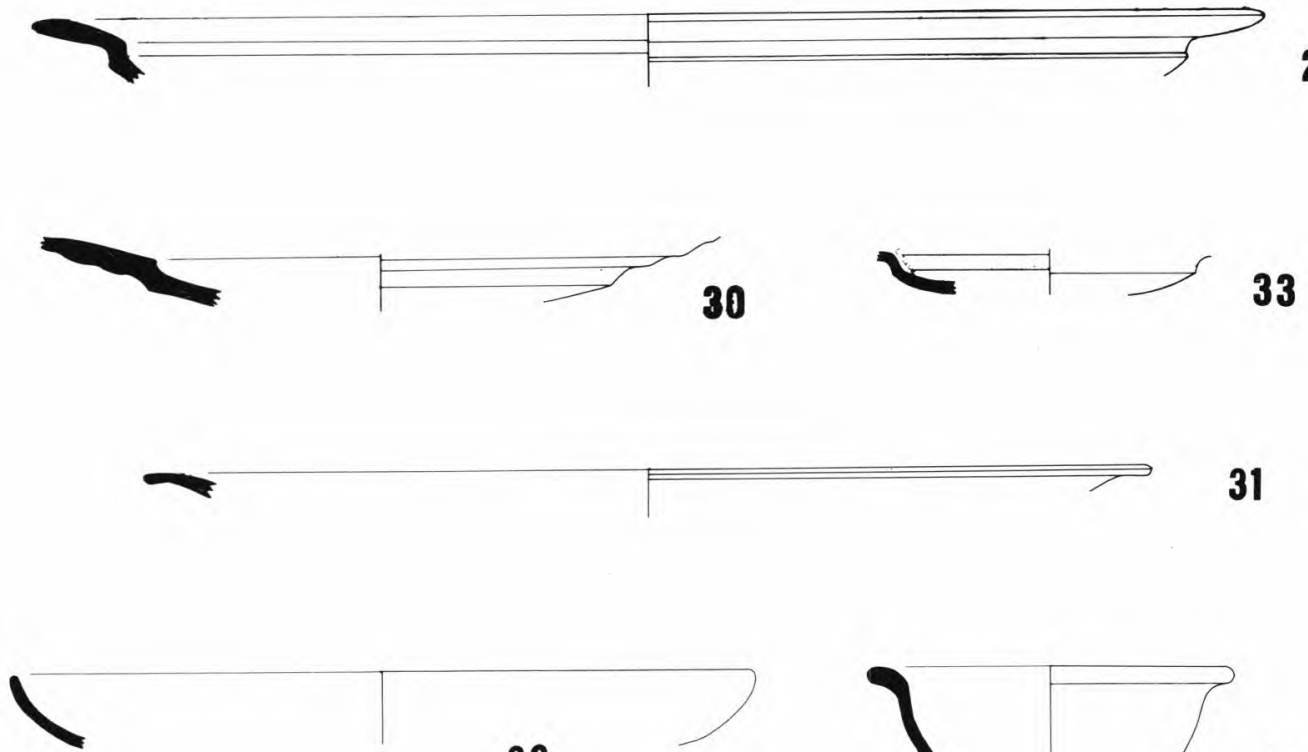

32
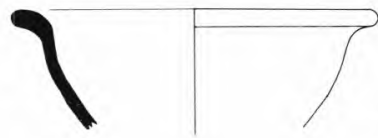

34

l

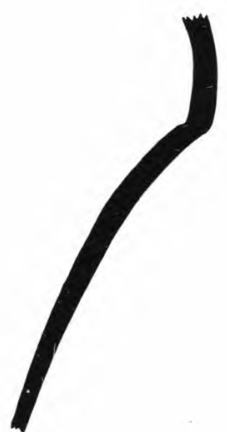

35
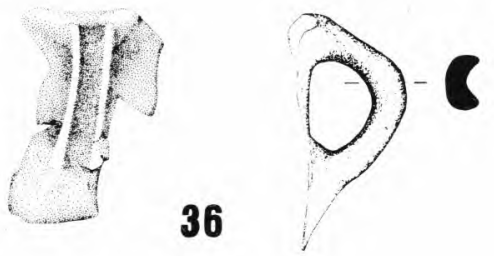

37

Esc. 1: 4 aprox. 
EST. VI
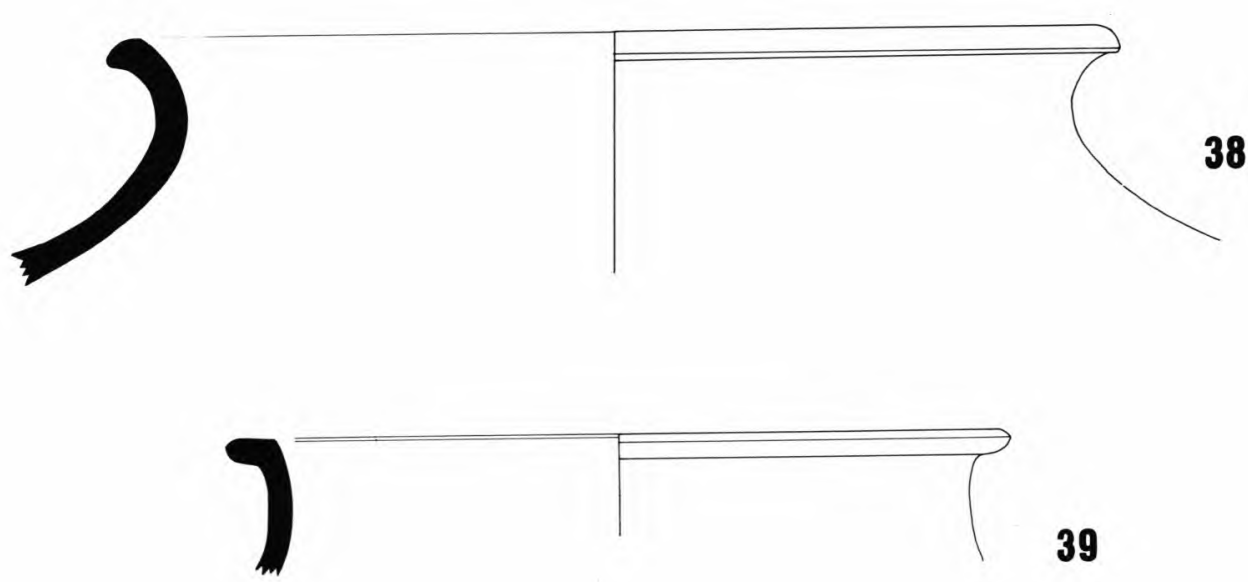

39
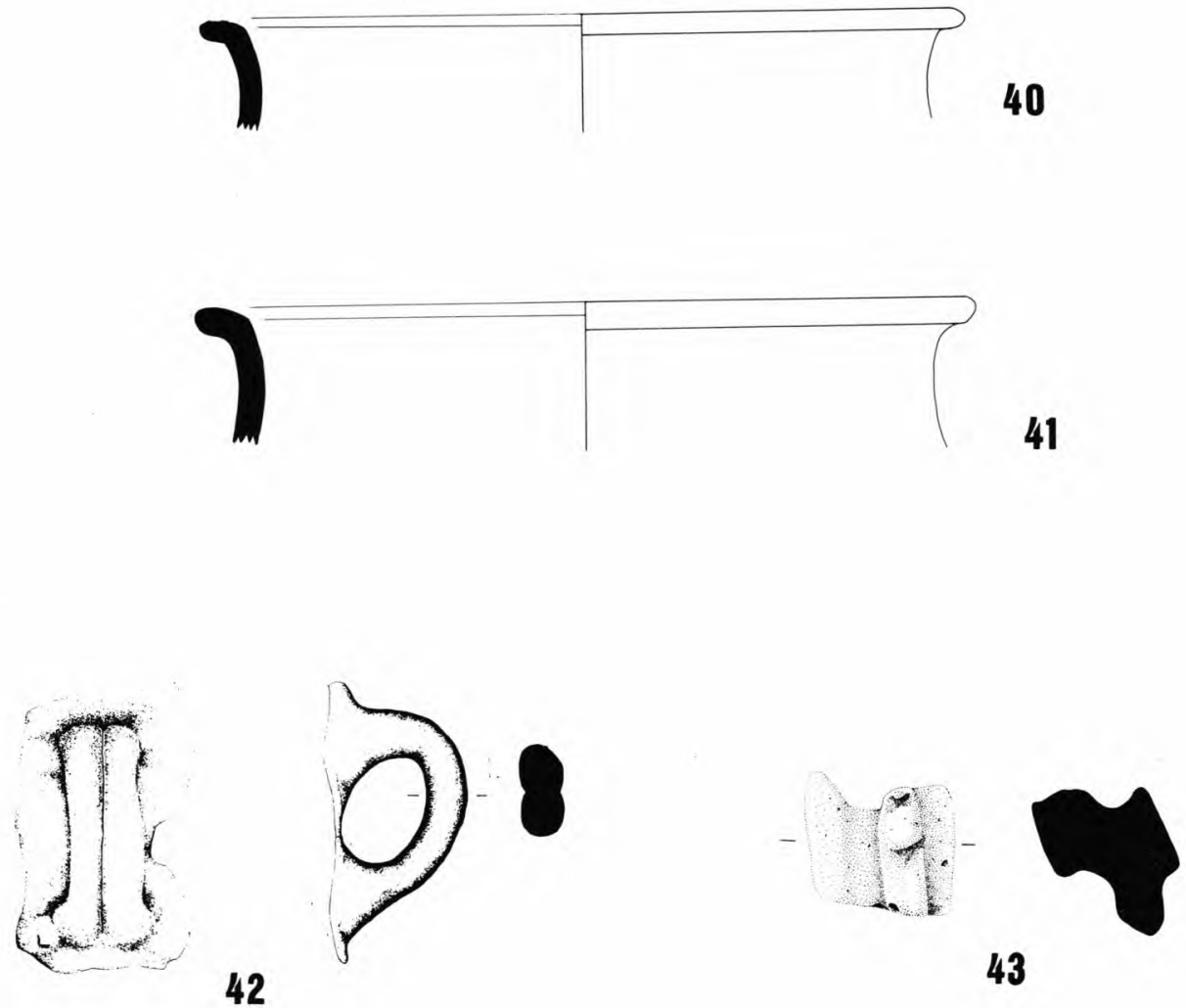

Esc. 1: 4 aprox. 